\title{
Magnetic Properties of Pr-Fe-Co-B Bonded HDDR Magnets with Alloying Additions
}

\author{
Eguiberto Galego*, Hidetoshi Takiishi, Rubens Nunes de Faria Jr. \\ Grupo de Materiais Magneticos, Instituto de Pesquisas Energéticas e Nucleares - IPEN, \\ Centro de Ciencia e Tecnologia de Materiais - CCTM, \\ Av. Prof. Lineu Prestes, 2242, Cid. Universitária, 05508-000 São Paulo - SP, Brazil
}

Received: February 13, 2007; Revised: July 24, 2007

\begin{abstract}
Microstructures and magnetic properties of $\mathrm{Pr}-\mathrm{Fe}-\mathrm{Co}-\mathrm{B}$ bonded magnets were investigated. The magnets can be represented by the formulae, $\operatorname{Pr}_{14} \mathrm{Fe}_{63.9} \mathrm{Co}_{16} \mathrm{~B}_{6} \mathrm{M}_{0.1}\left(\mathrm{M}=\mathrm{Ti}, \mathrm{V}, \mathrm{Cr}, \mathrm{Ni}, \mathrm{Zr}, \mathrm{Nb}\right.$ or Mo), $\mathrm{Pr}_{14} \mathrm{Fe}_{63.8} \mathrm{Co}_{16} \mathrm{~B}_{6} \mathrm{Nb}_{0.1} \mathrm{~T}_{0.1}(\mathrm{~T}=\mathrm{Al}$, $\mathrm{Si}, \mathrm{P}, \mathrm{Cu}$ or $\mathrm{Ga}$ ) and $\mathrm{Pr}_{14} \mathrm{Fe}_{63.6} \mathrm{Co}_{16} \mathrm{~B}_{6} \mathrm{Nb}_{0.1} \mathrm{R}_{0.3}(\mathrm{R}=\mathrm{Gd}, \mathrm{Tb}$ or $\mathrm{Dy})$. The effects of additions on the magnetic properties of PrFeCoB-based magnets have been studied. Magnetically hard powders have been produced from homogenised alloys using the hydrogenation, disproportionation, desorption and recombination (HDDR) process. The HDDR powders were isostatically pressed and bonded with cyanoacrylate adhesive to form permanent magnets.
\end{abstract}

Keywords: Pr-based alloys, magnetic materials, hydrides, magnetic properties, PACS: 71.20.Eh

\section{Introduction}

Neodymium- and praseodymium-based bonded magnets can be successfully prepared by the HDDR process ${ }^{1-17}$. Isotropic magnets are prepared using the basic alloy without additions and anisotropic with the additions of cobalt, gallium, zirconium and niobium. In the past, vanadium, chromium, aluminium have only been added to neodymium based bonded HDDR magnets ${ }^{18}$. In the present work, a further study has been carried out on these materials with various additions (Al, Si, P, Ti, V, Cr, Ni, Cu, Ga, Zr, Nb, Mo, Gd, Tb or Dy). A $\mathrm{Pr}_{14} \mathrm{Fe}_{64} \mathrm{Co}_{16} \mathrm{~B}_{6}$ alloy has been used as the base alloy for the additions and included in this study as a standard reference. A standard HDDR process appropriated for praseodymium-based bonded magnets ${ }^{11}$ has also been used in the present work.

It is well established that each particular composition requires its own set of processing parameters as the thermodynamic stability and microstructure of the parent compound is modified in a specific manner by the addition of a certain element. It is also known that anisotropy can be achieved by appropriate processing and for 2-14-1 compounds, without the addition of dopants. It has been reported that to process $\operatorname{Pr}_{13.7} \mathrm{Dy}_{1.0} \mathrm{Fe}_{63.5} \mathrm{Co}_{16.7} \mathrm{~B}_{6} \mathrm{Nb}_{0.1}$ HDDR magnets with better magnetic properties, higher hydrogen pressure is necessary than that used for processing Dy-free magnets ${ }^{17}$. A number of variables affect the HDDR process ${ }^{4}$ and, therefore, it is reasonable to use processing conditions that have yielded better results in the past and then seek the dopant that imparts the best magnetic properties. The HDDR treatment used in this investigation for the Pr-based alloys is very convenient because it uses a moderate temperature, a relatively low hydrogen pressure and rapid cooling rate. For the present processing conditions, that uses a straightforward HDDR treatment, finding an element that induces high anisotropy or high coercivity was considered to be very important.

\section{Experimental}

Various commercial alloys were investigated after a homogenization treatment in vacuum at $1100{ }^{\circ} \mathrm{C}$ for 20 hours. The chemical analyses of the as-cast alloys are given in Table 1. As per the supplier's specification, the alloys contain neodymium $(0.2 \sim 0.7 \mathrm{wt}$. (\%)), aluminium (0.02 0.2 wt. (\%)) and silicon (0.01 0.04 wt. (\%)) as an impurity.
The analysed amount of phosphorous in the $\operatorname{Pr}_{14} \mathrm{Fe}_{63.8} \mathrm{Co}_{16} \mathrm{~B}_{6} \mathrm{Nb}_{0.1} \mathrm{P}_{0.1}$ alloy is much less than that specified in the formula. According to the supplier the added phosphorous would not go into solution to any significant degree and instead formed an insoluble phosphate slag on the melt surface. Hence, the $\operatorname{Pr}_{14} \mathrm{Fe}_{\text {bal }} \mathrm{Co}_{16} \mathrm{~B}_{6} \mathrm{Nb}_{0.1} \mathrm{P}_{0.1}$ alloy does contain some phosphorous, but at somewhat lower level $(\sim 0.01 \mathrm{wt} .(\%))$ than that suggested by the nominal composition $(0.05 \mathrm{wt} .(\%))$.

The following procedure was adopted to produce the Pr-based bonded magnets via the HDDR process ${ }^{11-18}$. The annealed alloys were crushed into coarse lumps and $8 \mathrm{~g}$ batches were placed in the HDDR reactor. This reactor was then evacuated to the backing-pump pressure $\left(\sim 10^{-1} \mathrm{mbar}\right)$ and hydrogen introduced until the pressure of $0.097 \mathrm{MPa}$. The temperature of the reactor was held at $100{ }^{\circ} \mathrm{C}$ for 30 minutes to provide sufficient time for the hydrogen decrepitation (HD) reaction to go to completion. The reactor was then heated to $770{ }^{\circ} \mathrm{C}$ at $15^{\circ} \mathrm{C} / \mathrm{min}$ and further up to the desorption temperature $\left(860{ }^{\circ} \mathrm{C}\right.$ ) at $5^{\circ} \mathrm{C} / \mathrm{min}$, with a dwell time of 15 minutes prior to desorption ${ }^{11}$. Subsequent desorption and recombination was carried out under vacuum at the same temperature until a pressure of $10^{-1} \mathrm{mbar}$ was achieved ( $<10$ minutes). Rapid cooling of the material was carried out by removing the furnace from the HDDR reactor and by coupling a water-cooled copper coil to the reactor tube. The resultant powder was crushed in air until all the material passed through a $<75 \mu \mathrm{m}$ sieve. The fine powder was subsequently encapsulated in a small cylindrical rubber bag, pulsed in a magnetic field of $6 \mathrm{~T}$ and pressed isostatically at $200 \mathrm{MPa}$ (isotropic magnets were pressed without pulsing). The resultant green compacts were consolidated by immersion (vacuum impregnated) in cyanoacrylate adhesive with a low viscosity (3 Pa s) and heating to $70{ }^{\circ} \mathrm{C}$. The bonded sample was then allowed to cool to room temperature and the excess material removed to yield a cylindrical magnet $\left(\rho=5.0 \pm 0.3 \mathrm{~g} . \mathrm{cm}^{-3}\right)$. Magnetic characterization of the HDDR magnets was carried out using a permeameter (accuracy: $2 \%$ ). Measurements were performed after saturation in a pulsed field of $6 \mathrm{~T}$. Remanence values have been normalized assuming $100 \%$ density $\left(7.5 \mathrm{~g} . \mathrm{cm}^{-3}\right)$ for the HDDR sample and by also considering a linear relationship between density and remanence. 
Table 1. Composition of the as-cast praseodymium-based alloys.

\begin{tabular}{|c|c|c|c|c|c|c|}
\hline \multirow{2}{*}{$\begin{array}{l}\text { Nominal composition } \\
\text { (at \%) }\end{array}$} & \multicolumn{6}{|c|}{ Analyzed composition (wt. (\%)) } \\
\hline & Pr* & $\mathrm{Fe}$ & Co & $\mathrm{B}$ & $\mathrm{Nb}$ & $\mathrm{M} / \mathrm{T}$ \\
\hline $\mathrm{Pr}_{14} \mathrm{Fe}_{\text {bal }} \mathrm{Co}_{16} \mathrm{~B}_{6}$ & 30.01 & 54.56 & 14.31 & 1.01 & - & \\
\hline $\mathrm{Pr}_{14} \mathrm{Fe}_{\text {bal }} \mathrm{Co}_{16} \mathrm{~B}_{6} \mathrm{Ti}_{0.1}$ & 29.83 & 54.76 & 25 & 0.98 & - & 0.07 \\
\hline $\mathrm{Pr}_{14} \mathrm{Fe}_{\text {bal }} \mathrm{Co}_{16} \mathrm{~B}_{6} \mathrm{~V}_{0.1}$ & 30.09 & 54.37 & 14.40 & 1.01 & - & 0.06 \\
\hline $\mathrm{Pr}_{14} \mathrm{Fe}_{\text {bal }} \mathrm{Co}_{16} \mathrm{~B}_{6} \mathrm{Cr}_{0.1}$ & 30.29 & 54.08 & 14.44 & 0.96 & - & 0.08 \\
\hline $\mathrm{Pr}_{14} \mathrm{Fe}_{\mathrm{bal}} \mathrm{Co}_{16} \mathrm{~B}_{6} \mathrm{Ni}_{0.1}$ & 30.08 & 54.40 & 14.35 & 1.00 & - & 0.11 \\
\hline $\mathrm{Pr}_{14} \mathrm{Fe}_{\mathrm{bal}} \mathrm{Co}_{16} \mathrm{~B}_{6} \mathrm{Zr}_{0.1}$ & 30.06 & 54.32 & 14.42 & 1.01 & - & 0.11 \\
\hline $\mathrm{Pr}_{14} \mathrm{Fe}_{\text {bal }} \mathrm{Co}_{16} \mathrm{~B}_{6} \mathrm{Mo}_{0.1}$ & 30.35 & 53.89 & 14.51 & 1.00 & - & 0.16 \\
\hline $\mathrm{Pr}_{14} \mathrm{Fe}_{\text {bal }} \mathrm{Co}_{16} \mathrm{~B}_{6} \mathrm{Nb}_{0.1}$ & 30.35 & 54.11 & 14.34 & 0.96 & - & 0.14 \\
\hline $\mathrm{Pr}_{14} \mathrm{Fe}_{\mathrm{bal}} \mathrm{Co}_{16} \mathrm{~B}_{6} \mathrm{Nb}_{0.1} \mathrm{Al}_{0.1}$ & 30.33 & 54.18 & 14.24 & 0.99 & 0.18 & 0.02 \\
\hline $\mathrm{Pr}_{14} \mathrm{Fe}_{\text {bal }} \mathrm{Co}_{16} \mathrm{~B}_{6} \mathrm{Nb}_{0.1} \mathrm{Si}_{0.1}$ & 30.07 & 54.36 & 14.14 & 1.00 & 0.16 & 0.07 \\
\hline $\mathrm{Pr}_{14} \mathrm{Fe}_{\text {bal }} \mathrm{Co}_{16} \mathrm{~B}_{6} \mathrm{Nb}_{0.1} \mathrm{P}_{0.1}$ & 30.49 & 53.86 & 14.33 & 1.02 & 0.13 & 0.01 \\
\hline $\mathrm{Pr}_{14} \mathrm{Fe}_{\mathrm{bal}} \mathrm{Co}_{16} \mathrm{~B}_{6} \mathrm{Nb}_{0.1} \mathrm{Cu}_{0.1}$ & 30.51 & 53.79 & 14.25 & 0.99 & 0.15 & 0.13 \\
\hline $\mathrm{Pr}_{14} \mathrm{Fe}_{\text {bal }} \mathrm{Co}_{16} \mathrm{~B}_{6} \mathrm{Nb}_{0.1} \mathrm{Ga}_{0.1}$ & 30.44 & 53.85 & 14.28 & 1.00 & 0.14 & 0.11 \\
\hline $\mathrm{Pr}_{14} \mathrm{Fe}_{\text {bal }} \mathrm{Co}_{16} \mathrm{~B}_{6} \mathrm{Nb}_{0.1} \mathrm{Gd}_{0.3}$ & 29.65 & 54.22 & 14.22 & 1.02 & 0.14 & 0.69 \\
\hline $\mathrm{Pr}_{14} \mathrm{Fe}_{\mathrm{bal}} \mathrm{Co}_{16} \mathrm{~B}_{6} \mathrm{Nb}_{0.1} \mathrm{~Tb}_{0.3}$ & 29.94 & 54.05 & 14.16 & 0.98 & 0.12 & 0.71 \\
\hline $\mathrm{Pr}_{14} \mathrm{Fe}_{\mathrm{bal}} \mathrm{Co}_{16} \mathrm{~B}_{6} \mathrm{Nb}_{0.1} \mathrm{Dy}_{0.3}$ & 29.61 & 54.33 & 14.23 & 0.97 & 0.14 & 0.65 \\
\hline
\end{tabular}

(* $\mathrm{Pr}+\sim 0.3$ wt. $(\%) \mathrm{Nd})$.

Previously Pr-based HDDR magnets prepared in our laboratory used an isostatic press and paraffin as the bonding agent. In this work cyanoacrylate adhesive has been used with no significant difference (less than the measurement error) in the magnetic properties but with considerable improvement in the mechanical resistance of the samples (isostatically pressed and paraffin or wax or bonded magnets cannot withstand more than two demagnetisations in the permeameter without loosing integrity). The microstructures of the HDDR material were examined in a scanning electron microscope.

\section{Results and Discussion}

Figures 1 shows the percentage variation on the remanence of the PrFeCoB-based HDDR bonded magnets as a function of the atomic number $(\mathrm{Z})$ of the addition element. These percentage variations were calculated taking the remanence of an isotropic $\operatorname{Pr}_{14} \mathrm{Fe}_{\text {bal }} \mathrm{Co}_{16} \mathrm{~B}_{6}$ magnet as a reference $(0.59 \mathrm{~T})$. Figure 2 shows the percentage variation on the intrinsic coercivity of these magnets also as a function of the atomic number of the addition element. Again, these percentage variations were calculated taking the intrinsic coercivity of an isotropic $\operatorname{Pr}_{14} \mathrm{Fe}_{\text {bal }} \mathrm{Co}_{16} \mathrm{~B}_{6}$ magnet as a reference $(0.94 \mathrm{~T})$.

\subsection{The effect of Ti, $\mathrm{V}, \mathrm{Cr}$ or Ni additions}

Titanium addition increased the remanence slightly but decreased the intrinsic coercivity, also slightly. Conversely, vanadium additon enhanced the intrinsic coercivity considerably $(1.17 \pm 0.02 \mathrm{~T})$. Data about $\mathrm{Nd}_{16} \mathrm{Fe}_{66.275} \mathrm{Co}_{11.6} \mathrm{~B}_{6} \mathrm{~V}_{0.125}$ HDDR magnets, reported previously, showed superior remanence and inferior coercivity ${ }^{18}$. Chromium addition led to an increase in remanence $(0.67 \pm 0.01 \mathrm{~T})$, but only a slight increase in the coercivity of the Pr-based magnets. Previously reported data about $\mathrm{Nd}_{16} \mathrm{Fe}_{66.275} \mathrm{Co}_{11.6} \mathrm{~B}_{6} \mathrm{Cr}_{0.125}$ HDDR magnets showed slightly higher remanence and similar coercivity ${ }^{20}$. Better intrinsic coercivity can be expected in the $\mathrm{Nd}$-based magnet since the rare earth content is higher than that in the $\operatorname{Pr}_{14} \mathrm{Fe}_{63.9} \mathrm{Co}_{16} \mathrm{~B}_{6} \mathrm{Cr}_{0.1}$ bonded magnet prepared in this investigation (due to the improved magnetic isolation in the Nd-based magnets). The addition of nickel induced a substantial anisotropy in the HDDR bonded magnets and also enhanced the intrinsic coercivity to a maximum value $(1.18 \pm 0.02 \mathrm{~T})$.

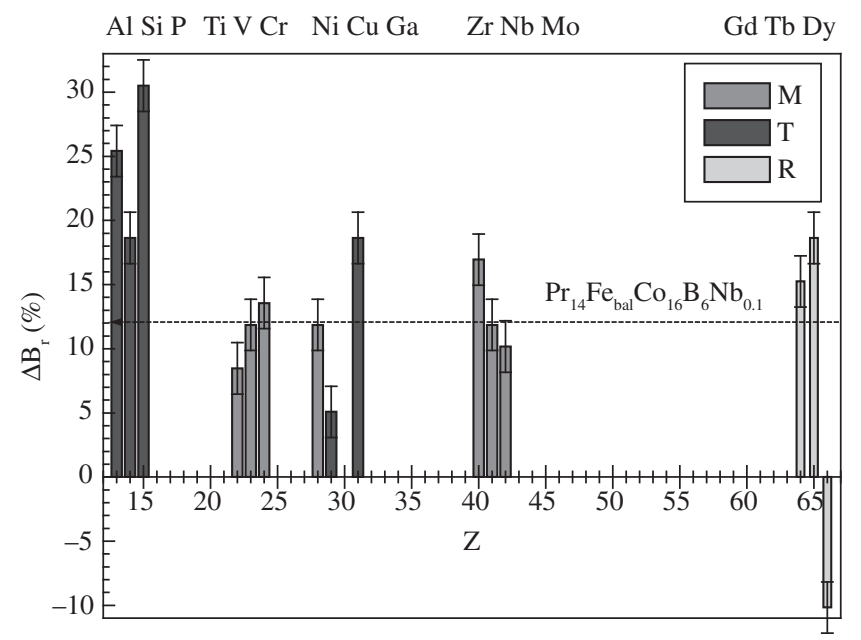

Figure 1. Remanence variation of the $\operatorname{Pr}_{14} \mathrm{Fe}_{63.9} \mathrm{Co}_{16} \mathrm{~B}_{6} \mathrm{M}_{0.1}, \mathrm{Pr}_{14} \mathrm{Fe}_{63.8} \mathrm{Co}_{16} \mathrm{~B}_{6}$ $\mathrm{Nb}_{0.1} \mathrm{~T}_{0.1}$ and $\operatorname{Pr}_{14} \mathrm{Fe}_{63.6} \mathrm{Co}_{16} \mathrm{~B}_{6} \mathrm{Nb}_{0.1} \mathrm{R}_{0.3}$ HDDR bonded magnets plotted against the atomic number of the addition element.

Al Si P Ti V Cr Ni Cu Ga Zr Nb Mo

Gd Tb Dy

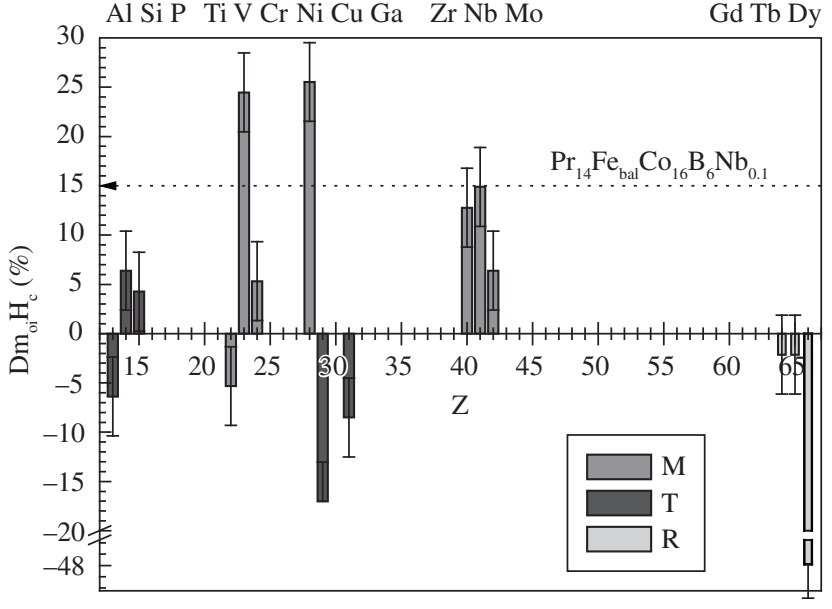

Figure 2. Coercivity variation of the $\operatorname{Pr}_{14} \mathrm{Fe}_{63.9} \mathrm{Co}_{16} \mathrm{~B}_{6} \mathrm{M}_{0.1}, \mathrm{Pr}_{14} \mathrm{Fe}_{63.8} \mathrm{Co}_{16} \mathrm{~B}_{6} \mathrm{Nb}_{0.1}$ $\mathrm{T}_{0.1}$ and $\mathrm{Pr}_{14} \mathrm{Fe}_{63.6} \mathrm{Co}_{16} \mathrm{~B}_{6} \mathrm{Nb}_{0.1} \mathrm{R}_{0.3}$ HDDR bonded magnets plotted against the atomic number of the addition element.

\subsection{The effect of $\mathrm{Zr}, \mathrm{Nb}$ or Mo additions}

Zirconium and niobium addition enhanced the remanence and the coercivity of the HDDR magnets. The former showed a superior remanence $(0.69 \pm 0.01 \mathrm{~T})$ whereas the latter showed higher coercivity $(1.08 \pm 0.02 \mathrm{~T})$. In sintered magnets, $\mathrm{Nb}$ refined the magnetic grains and formed a Nb-Fe-B phase in the grain boundaries ${ }^{19}$. This refining effect of $\mathrm{Nb}$ has also been reported to $\mathrm{Zr}^{20}$. The reasonable coercivity in the $\mathrm{Zr}$ - or $\mathrm{Nb}$-containg HDDR magnets was attributed to this effect. The addition of molybdenum resulted in a moderate increase in these magnetic properties. It was considered that $\mathrm{Zr}, \mathrm{Nb}$ or Mo have a similar behavior in the HDDR process. $\mathrm{Zr}$ enhanced the remanence due to a diminution of the disproportionation temperature (Nd-based HDDR magnets) $)^{10}$.

\subsection{The effect of Al, Si or $P$ additions}

Aluminium addition in the $\mathrm{Nb}$-containing magnets increased the remanence $(0.74 \pm 0.01 \mathrm{~T})$ at the expenses of a reduction in the coercivity. In sintered $\mathrm{Nd}$-based magnets, $\mathrm{Al}$ addition combined with the $\mathrm{Co}$ 
presence increased the coercivity due to the formation of non-magnetic Laves phases, $\mathrm{Nd}(\mathrm{Fe}, \mathrm{Co})_{2}$, in the grains boundaries and diminished the remanence due to the substitution of Fe with this element in the matrix phase $^{21}$. In the HDDR magnets the opposite occurred, suggesting that small amounts of $\mathrm{Al}$ stayed in the matrix phase as nucleation sites to induce anisotropy and in the grain boundaries as reverse domains nucleation regions. Silicon also induced considerably anisotropy in the HDDR magnets and led to a slight improvement in the intrinsic coercivity. It is well known that, $\mathrm{Fe}$ and $\mathrm{Si}$ combine to form a soft magnetic phase, which is detrimental to the magnet coercivity. This was not the case in the $\operatorname{Pr}_{14} \mathrm{Fe}_{\text {bal }} \mathrm{Co}_{16} \mathrm{~B}_{6} \mathrm{Nb}_{0.1} \mathrm{Si}_{0.1}$ bonded magnets.

Phosphorus addition in these bonded magnets led to the highest remanence value $(0.77 \pm 0.01 \mathrm{~T})$ and also improved somewhat the intrinsic coercivity. The remanence of the $\operatorname{Pr}_{14} \mathrm{Fe}_{\text {bal }} \mathrm{Co}_{16} \mathrm{~B}_{6} \mathrm{Nb}_{0.1} \mathrm{P}_{0.1}$ magnet was much higher than that of the $\operatorname{Pr}_{14} \mathrm{Fe}_{\text {bal }} \mathrm{Co}_{16} \mathrm{~B}_{6} \mathrm{Nb}_{0.1}$ magnet, showing that the combination $\mathrm{Nb} / \mathrm{P}$ was very efficient to induce high anisotropy. The addition of $\mathrm{P}$ to an alloy $\left(\mathrm{Pr}_{7} \mathrm{~Tb}_{1} \mathrm{Fe}_{87-\mathrm{x}} \mathrm{Nb}_{0.5} \mathrm{Zr}_{0.5} \mathrm{P}_{\mathrm{x}} \mathrm{B}_{4}\right)$ prepared by melt-spinning led to the formation of a Pr-P phase ${ }^{22}$. This diminished the melting point of the alloy and refined the alloy microstructure. The coercivity of the $\operatorname{Pr}_{14} \mathrm{Fe}_{\text {bal }} \mathrm{Co}_{16} \mathrm{~B}_{6} \mathrm{Nb}_{0.1} \mathrm{P}_{0.1}$ magnet was inferior to that of the $\operatorname{Pr}_{14} \mathrm{Fe}_{\text {bal }} \mathrm{Co}_{16} \mathrm{~B}_{6} \mathrm{Nb}_{0.1}$ magnet indicating that the combination $\mathrm{Nb} / \mathrm{P}$ was inefficient to improve the coercivity, although both being refining elements.

\subsection{The effect of $\mathrm{Cu}$ or $\mathrm{Ga}$ additions}

Copper addition induced some anisotropy, however, the remanence of the $\operatorname{Pr}_{14} \mathrm{Fe}_{\text {bal }} \mathrm{Co}_{16} \mathrm{~B}_{6} \mathrm{Nb}_{0.1} \mathrm{Cu}_{0.1}$ magnet was still inferior to that of the $\operatorname{Pr}_{14} \mathrm{Fe}_{\text {bal }} \mathrm{Co}_{16} \mathrm{~B}_{6} \mathrm{Nb}_{0.1}$ magnet. On the other hand, copper addition decreased dramatically the intrinsic coercivity. A microstructural observation showed that the $\operatorname{Pr}_{14} \mathrm{Fe}_{\text {bal }} \mathrm{Co}_{16} \mathrm{~B}_{6} \mathrm{Nb}_{0.1} \mathrm{Cu}_{0.1}$ HDDR powder exhibited a grain size 10 times bigger than that typical of the others processed alloys. A comparison is given in Figures $3 \mathrm{a}$ and b. It has been reported that copper reduces the melting temperature of the Pr-rich phase ${ }^{23}$. This could explain the larger grain size of the HDDR material and the low coercivity found in the $\mathrm{Cu}$-containing magnets. Gallium addition also improved considerably the remanence $(0.70 \pm 0.01 \mathrm{~T})$ but was detrimental to the coercivity. An optimum processing hydrogen pressure was necessary for obtaining high intrinsic coercivity in Nd-based bonded magnets with $\mathrm{Ga}$ addition (although with a reduction in the remanence) ${ }^{24}$.

\subsection{The effect of $G d, T b$ or Dy additions}

Except for Dy, all alloying elements increased the remanence of the Pr-based HDDR magnets by inducing distinct degrees of anisotropy. Dysprosium was detrimental for both, remanence and coercivity. The addition of $\mathrm{Gd}$ and $\mathrm{Tb}$ in these magnets induced anisotropy although with a rather low coercivity. It has been reported that a higher processing hydrogen pressure is necessary for obtaining high coercivity in PrFeCoBDy-based bonded magnets ${ }^{17}$. This also could be the case for $\mathrm{Gd}$ and $\mathrm{Tb}$. However, $\operatorname{Pr}_{13.7} \mathrm{Dy}_{1.0} \mathrm{Fe}_{63.5} \mathrm{Co}_{16.7} \mathrm{~B}_{6} \mathrm{Nb}_{0.1}$ magnets processed at an optimum hydrogen pressure exhibited high coercivity but were unable to develop high anisotropy ${ }^{17}$. It is plausible to assume that the low intrinsic coercivity related with the presence of $\mathrm{Al}, \mathrm{Ti}, \mathrm{Cu}, \mathrm{Ga}, \mathrm{Gd}$ or Tb, could be improved by changing the HDDR processing conditions (hydrogen pressure and/or reaction temperature). Table 2 summarizes the magnetic properties of the Pr-based bonded magnets prepared using the HDDR powder and cyanoacrylate adhesive. Further microstructural studies on all the starting alloys, and corresponding HDDR powders are underway and the results will be presented and discussed in detail in a forthcoming paper.

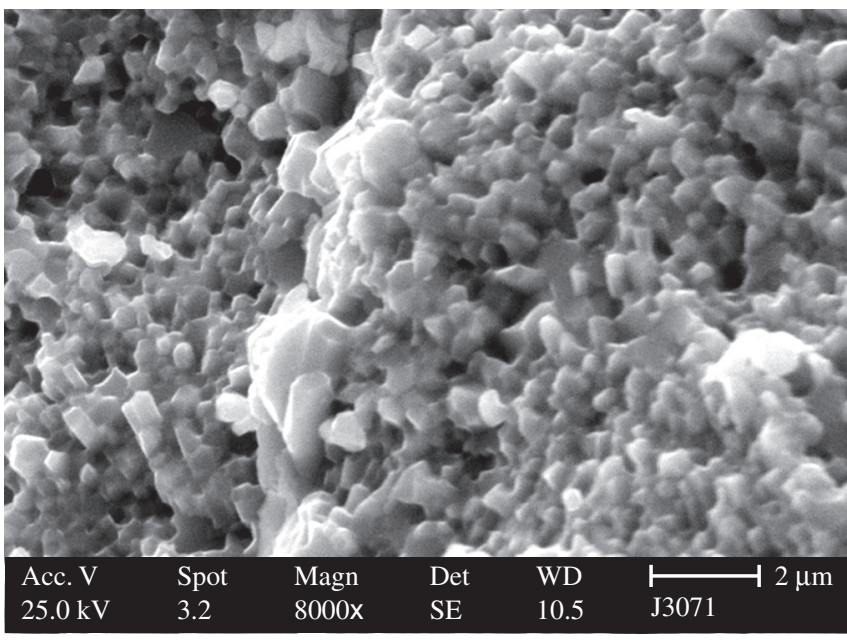

(a)

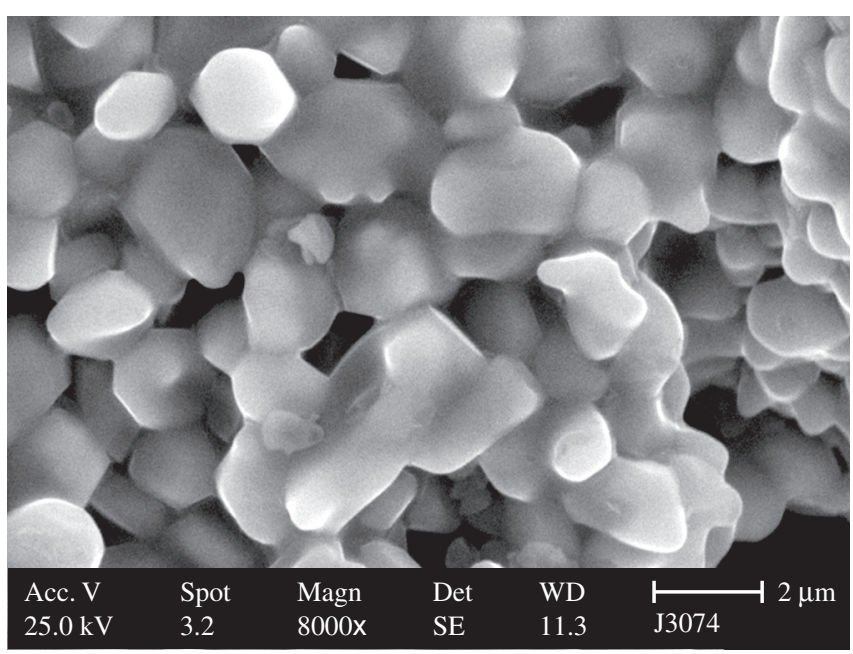

(b)

Figure 3. Secondary electron image of HDDR material prepared from the homogenized alloy: a) $\mathrm{Pr}_{14} \mathrm{Fe}_{\text {bal }} \mathrm{Co}_{16} \mathrm{~B}_{6} \mathrm{Nb}_{0.1} \mathrm{P}_{0.1}$; and b) $\mathrm{Pr}_{14} \mathrm{Fe}_{\text {bal }} \mathrm{Co}_{16} \mathrm{~B}_{6} \mathrm{Nb}_{0.1} \mathrm{Cu}_{0.1}$ (fracture surface).

\section{Conclusions}

The results indicate that vanadium, nickel, zirconium and niobium can be used as a single addition to $\operatorname{Pr}_{14} \mathrm{Fe}_{\text {bal }} \mathrm{Co}_{16} \mathrm{~B}_{6}$ HDDR bonded magnets. Niobium and zirconium induce considerably anisotropy whereas vanadium and nickel enhance the intrinsic coercivity. It has also been shown that when the second element ( $\mathrm{Al}, \mathrm{Si}, \mathrm{P}, \mathrm{Cu}$ or $\mathrm{Ga}$ ) is added to the $\operatorname{Pr}_{14} \mathrm{Fe}_{\text {bal }} \mathrm{Co}_{16} \mathrm{~B}_{6} \mathrm{Nb}_{0.1}$ alloy only phosphorus and silicon cause the significant increase in remanence without loosing coercivity. The $\operatorname{Pr}_{14} \mathrm{Fe}_{\text {bal }} \mathrm{Co}_{16} \mathrm{~B}_{6} \mathrm{Nb}_{0.1} \mathrm{P}_{0.1}$ HDDR bonded magnet exbited the highest remanence whereas the $\operatorname{Pr}_{14} \mathrm{Fe}_{\text {bal }} \mathrm{Co}_{16} \mathrm{~B}_{6} \mathrm{Ni}_{0.1}$ magnet showed the highest coercivity. Under the present processing conditions rare earth addition (Gd, $\mathrm{Tb}$ or Dy) to the $\operatorname{Pr}_{14} \mathrm{Fe}_{\text {bal }} \mathrm{Co}_{16} \mathrm{~B}_{6} \mathrm{Nb}_{0.1}$ alloy was detrimental to the intrinsic coercivity of the bonded magnets.

\section{Acknowledgments}

The authors wish to thank FAPESP and IPEN-CNEN/SP for the financial support and infrastructure made available to carry out this investigation. 
Table 2. Remanence and coercivity of $\operatorname{Pr}_{14} \mathrm{Fe}_{63.9} \mathrm{Co}_{16} \mathrm{~B}_{6} \mathrm{M}_{0.1}, \operatorname{Pr}_{14} \mathrm{Fe}_{63.8} \mathrm{Co}_{16} \mathrm{~B}_{6} \mathrm{Nb}_{0.1} \mathrm{~T}_{0.1}$ and $\operatorname{Pr}_{14} \mathrm{Fe}_{63.8} \mathrm{Co}_{16} \mathrm{~B}_{6} \mathrm{Nb}_{0.1} \mathrm{R}_{0.3}$ HDDR bonded magnets.

\begin{tabular}{|c|c|c|c|c|}
\hline Composition & $\mathrm{B}_{\mathrm{r}}(\mathrm{T})$ & $\Delta \mathrm{B}_{\mathrm{r}}(\%)$ & $\mu_{\mathrm{oi}} \mathrm{H}_{\mathrm{c}}(\mathrm{T})$ & $\Delta \mu_{\mathrm{oi}} \mathrm{H}_{\mathrm{c}}(\%)$ \\
\hline $\mathrm{Pr}_{14} \mathrm{Fe}_{\mathrm{bal}} \mathrm{Co}_{16} \mathrm{~B}_{6}$ (isotropic) & $0.59 \pm 0.01$ & - & $0.94 \pm 0.02$ & - \\
\hline $\mathrm{Pr}_{14} \mathrm{Fe}_{\text {bal }} \mathrm{Co}_{16} \mathrm{~B}_{6} \mathrm{Ti}_{0.1}$ & $0.64 \pm 0.01$ & $8.47 \pm 2$ & $0.89 \pm 0.02$ & $-5.32 \pm 4$ \\
\hline $\mathrm{Pr}_{14} \mathrm{Fe}_{\text {bal }} \mathrm{Co}_{16} \mathrm{~B}_{6} \mathrm{~V}_{0.1}$ & $0.66 \pm 0.01$ & $11.86 \pm 2$ & $1.17 \pm 0.02$ & $24.47 \pm 4$ \\
\hline $\mathrm{Pr}_{14} \mathrm{Fe}_{\text {bal }} \mathrm{Co}_{16} \mathrm{~B}_{6} \mathrm{Cr}_{0.1}$ & $0.67 \pm 0.01$ & $13.56 \pm 2$ & $0.99 \pm 0.02$ & $5.32 \pm 4$ \\
\hline $\mathrm{Pr}_{14} \mathrm{Fe}_{\text {bal }} \mathrm{Co}_{16} \mathrm{~B}_{6} \mathrm{Ni}_{0.1}$ & $0.66 \pm 0.01$ & $11.86 \pm 2$ & $1.18 \pm 0.02$ & $25.53 \pm 4$ \\
\hline $\mathrm{Pr}_{14} \mathrm{Fe}_{\text {bal }} \mathrm{Co}_{16} \mathrm{~B}_{6} \mathrm{Zr}_{0.1}$ & $0.69 \pm 0.01$ & $16.95 \pm 2$ & $1.06 \pm 0.02$ & $12.77 \pm 4$ \\
\hline $\mathrm{Pr}_{14} \mathrm{Fe}_{\text {bal }} \mathrm{Co}_{16} \mathrm{~B}_{6} \mathrm{Nb}_{0.1}$ & $0.66 \pm 0.01$ & $11.86 \pm 2$ & $1.08 \pm 0.02$ & $14.89 \pm 4$ \\
\hline $\mathrm{Pr}_{14} \mathrm{Fe}_{\text {bal }} \mathrm{Co}_{16} \mathrm{~B}_{6} \mathrm{Mo}_{0.1}$ & $0.65 \pm 0.01$ & $10.17 \pm 2$ & $1.00 \pm 0.02$ & $6.38 \pm 4$ \\
\hline $\mathrm{Pr}_{14} \mathrm{Fe}_{\text {bal }} \mathrm{Co}_{16} \mathrm{~B}_{6} \mathrm{Nb}_{0.1} \mathrm{Al}_{0.1}$ & $0.74 \pm 0.01$ & $25.42 \pm 2$ & $0.88 \pm 0.02$ & $-6.38 \pm 4$ \\
\hline $\mathrm{Pr}_{14} \mathrm{Fe}_{\text {bal }} \mathrm{Co}_{16} \mathrm{~B}_{6} \mathrm{Nb}_{0.1} \mathrm{Si}_{0.1}$ & $0.70 \pm 0.01$ & $18.64 \pm 2$ & $1.00 \pm 0.02$ & $6.38 \pm 4$ \\
\hline $\mathrm{Pr}_{14} \mathrm{Fe}_{\text {bal }} \mathrm{Co}_{16} \mathrm{~B}_{6} \mathrm{Nb}_{0.1} \mathrm{P}_{0.1}$ & $0.77 \pm 0.01$ & $30.51 \pm 2$ & $0.98 \pm 0.02$ & $4.26 \pm 4$ \\
\hline $\mathrm{Pr}_{14} \mathrm{Fe}_{\text {bal }} \mathrm{Co}_{16} \mathrm{~B}_{6} \mathrm{Nb}_{0.1} \mathrm{Cu}_{0.1}$ & $0.62 \pm 0.01$ & $5.08 \pm 2$ & $0.78 \pm 0.02$ & $-17.02 \pm 4$ \\
\hline $\mathrm{Pr}_{14} \mathrm{Fe}_{\text {bal }} \mathrm{Co}_{16} \mathrm{~B}_{6} \mathrm{Nb}_{0.1} \mathrm{Ga}_{0.1}$ & $0.70 \pm 0.01$ & $18.64 \pm 2$ & $0.86 \pm 0.02$ & $-8.51 \pm 4$ \\
\hline $\mathrm{Pr}_{14} \mathrm{Fe}_{\text {bal }} \mathrm{Co}_{16} \mathrm{~B}_{6} \mathrm{Nb}_{0.1} \mathrm{Gd}_{0.3}$ & $0.68 \pm 0.01$ & $15.25 \pm 2$ & $0.92 \pm 0.02$ & $-2.13 \pm 4$ \\
\hline $\mathrm{Pr}_{14} \mathrm{Fe}_{\text {bal }} \mathrm{Co}_{16} \mathrm{~B}_{6} \mathrm{Nb}_{0.1} \mathrm{~Tb}_{0.3}$ & $0.70 \pm 0.01$ & $18.64 \pm 2$ & $0.92 \pm 0.02$ & $-2.13 \pm 4$ \\
\hline $\mathrm{Pr}_{14} \mathrm{Fe}_{\text {bal }} \mathrm{Co}_{16} \mathrm{~B}_{6} \mathrm{Nb}_{0.1} \mathrm{Dy}_{0.3}$ & $0.53 \pm 0.01$ & $-10.17 \pm 2$ & $0.49 \pm 0.01$ & $-47.87 \pm 4$ \\
\hline
\end{tabular}

$\Delta \mathrm{B}_{\mathrm{r}}=[(\mathrm{Br} / 0.59)-1] 100 ; \Delta \mu_{\mathrm{oi}} \mathrm{H}_{\mathrm{c}}=\left[\left(\mu_{\mathrm{oi}} \mathrm{H}_{\mathrm{c}} / 0.94\right)-1\right] 100$.

\section{References}

1. Takeshita T, Nakayama R. Magnetic properties and microstructures of the $\mathrm{NdFeB}$ magnet powder produced by hydrogen treatment. In: Proceedings of the tenth Internat. Workshop on Rare Earth Magnets and Their Applications; 1989, Kyoto Japan. p. 551-557.

2. McGuiness PJ, Zang XJ, Yin XJ, Harris IR. Hydrogenation, Disproportionation and Desorption (HDD) - an effective processing route for $\mathrm{Nd}-\mathrm{Fe}-\mathrm{B}-\mathrm{type}$ magnets. Journal of the Less-Common Metals. 1990; 158(2):359-365.

3. Hirosawa S, Uehara M, Mino S, Ishigaki N, Tomida T. New aspects of $\mathrm{Nd}-\mathrm{Fe}-\mathrm{B}-$ based hydrogenation-disproportionation-desorption-recombination powders and anisotropic bonded magnets made from them: Microstructure and magnetic properties. Journal of Applied Physics. 1997; 81(8):4821-4826 Part 2B.

4. Gutfleisch O, Harris IR. Effect of grain size on magnetic properties and deformation behaviour of $\mathrm{NdFeB}$ magnets made by various preparation routes. In: Proceedings of the Fifteenth international workshop on rare-earth magnets and their applications; 1998, Aug 30 - Sept 3, Dresden, Germany; Frankfurt: Werkstoff-Informationsgesellschaft; 1998, p. 373-380.

5. Nakayama R, Takeshita T, Itakura M, Kuwano N, Oki K. MagneticProperties and Microstructures of the Nd-Fe-B Magnet Powder Produced by Hydrogen Treatment. Journal of Applied Physics. 1991; 70(7):3770-3774.

6. Nakayama R, Takeshita T, Itakura M, Kuwano N, Oki K. Microstructures And Crystallographic Orientation of Crystalline Grains in Anisotropic Nd-Fe-Co-B-(Ga or Zr) Magnet Powders Produced by the HydrogenationDecomposition-Desorption-Recombination Process. Journal of Applied Physics. 1994;76(1):412-417.

7. Nakayama R, Takeshita T. Magnetic-Properties and Microstructures of the Nd-Fe-B System During the Hydrogenation-DecompositionDesorption-Recombination Process. Journal of Applied Physics. 1993; 74(4):2719-2724.

8. Takeshita T, Morimoto K. Anisotropic Nd-Fe-B bonded magnets made from HDDR powders. Journal of Applied Physics. 1996; 79(8):5040-5044 Part 2A.

9. Pan W, Cui LY, Wang P, Zhou SX. Magnetic Properties of HDDR Processed $\left(\mathrm{Pr}_{1-\mathrm{x}} \mathrm{Nd}_{\mathrm{x}}\right)_{13} \mathrm{Fe}_{81} \mathrm{~B}_{6}$. In: Missell FP, Villas-Boas V, Rechenberg HR, Landgraf FJ, editors. Fourteenth International Workshop on Rare-Earth
Magnets and Their Applications, 1996 Sept 1-4, Sao Paulo, Brazil. Singapore: World Scientific Publishing Co. Pte. Ltd; 1996. p. 467-472.

10. Kim YB, Jeung WY. Hydrogen absorption and desorption behavior in Pr-Fe-B type alloys. Journal of Applied Physics. 1998; 83(11):6405-6407 Part 2.

11. Faria RN, Williams AJ, Harris IR. High anisotropy in Pr-Fe-CoB-Zr HDDR powders. Journal of Alloys and Compounds. 1999; 287(1-2)L10-L12.

12. Faria RN, Williams AJ, Harris IR. Permeameter measurements of anisotropic PrFeCoBZr hydrogenation disproportionation desorption and recombination (HDDR) magnets. Journal of Magnetism and Magnetic Materials. 1999; 202(2-3):349-353.

13. Faria RN, Brown DN, Harris IR. The influence of alloying additions and process parameters on the magnetic properties of PrFeB-based bonded magnets. Journal of Alloys and Compounds. 2000; 296(1-2):219-222.

14. Faria RN, Davies BE, Brown DN, Harris IR. Microstructural studies on Pr-Fe-B-Cu magnets produced by upset forging of cast ingot. Journal of Alloys and Compounds. 2000; 296(1-2):223-228.

15. Cannesan N, Brown DN, Williams AJ, Harris IR. The production and characterisation of highly anisotropic PrFeCoB-type HDDR powders. Journal of Magnetism and Magnetic Materials. 2001; 233(3):209-218.

16. Cannesan N, Brown DN, Williams AJ, Harris IR. The evolution of the disproportionated microstructure of PrFeB-based alloys. Journal of Magnetism and Magnetic Materials. 2002; 242-245:1372-1374 Part 2.

17. Takiishi H, Lima LF, Faria RN, Brown D N. The Effect of key Process Variantions Upon the Magnetic Properties of HDDR (Pr,Dy)-(Fe,Co)-B$\mathrm{Nb}$ Bonded Magnets. In: Hadjipanayis GC, Bonder MJ, editors. Proceedings of the seventeenth International Workshop on Rare Earth Magnets and Their Applications; 2002 August 18-22; Newark, Delaware, USA. Princeton: Rinton Press, Inc; 2002, p. 184-191.

18. Jurczyk M, Jakubowicz J, Gebel B, Handstein A, Gutfleisch O, Muller KH. Nd-2(Fe,Co,M)(14)B-type magnet powders produced by the HDDR process. Journal of Alloys and Compounds. 1999; 292(1-2):296-300.

19. RODEWALD W, WALL B. Structure and magnetic-properties of sintered $\mathrm{Nd}-\mathrm{Fe}-\mathrm{Nb}-\mathrm{B}$ magnets. Journal of Magnetism and Magnetic Materials. 1989; 80(1):57-60.

20. Faria RN, Castro ARM, Lima NB. Relation between grain alignment and magnetic properties of Pr-Fe-B sintered magnets. Journal of Magnetism and Magnetic Materials. 2002; 238(1):38-46. 
21. Mizoguchi T, Sakai I, Niu H, Inomata K. Nd-Fe-B-Co-Al Based Permanent-Magnets With Improved Magnetic-Properties And Temperature Characteristics. IEEE Transactions on Magnetics. 1986; 22(5):919-921.

22. Jin ZQ, Zhang Y, Wang HL, Klaessig A, Bonder M, Hadjipanayis GC. The improved magnetic properties in phosphorus substituted $\mathrm{Pr}-\mathrm{Fe}-\mathrm{P}-\mathrm{B}$ nanocomposites. Journal of Applied Physics. 2003; 93(10):6492-6494.
23. Noh TH, Jeung WY, Kang IK, Shin SH, Lee JJ. Magnetic properties of Pr-Fe-B alloy powders prepared by mechanical grinding. Journal of Applied Physics. 1991; 70(10):6591-6593

24. Gao JR, Song XP, Wang XT. Effects of reduced hydrogen pressure on magnetic properties of HDDR-treated $\mathrm{NdFeGaB}$ alloy powders. Journal Of Alloys And Compounds. 1998; 267(1-2):270-273. 
